\title{
Evaluation of Acute 13-Week Subchronic Toxicity and Genotoxicity of the Powdered Root of Tongkat Ali (Eurycoma longifolia Jack)
}

\author{
Ching-Hao Li, ${ }^{1,2}$ Jiunn-Wang Liao, ${ }^{3}$ Po-Lin Liao, ${ }^{4,5}$ Wei-Kuang Huang, ${ }^{4}$ Ling-Shan Tse, \\ Cheng-Hui Lin, ${ }^{4}$ Jaw-Jou Kang, ${ }^{5}$ and Yu-Wen Cheng ${ }^{4}$ \\ ${ }^{1}$ Department of Physiology, School of Medicine, College of Medicine, Taipei Medical University, Taipei, Taiwan \\ ${ }^{2}$ Graduate Institute of Medical Sciences, College of Medicine, Taipei Medical University, Taipei, Taiwan \\ ${ }^{3}$ Graduate Institute of Veterinary Pathology, College of Veterinary Medicine, National Chung Hsing University, Taichung, Taiwan \\ ${ }^{4}$ School of Pharmacy, Taipei Medicine University, 250 Wu-Hsing Street, Taipei 11031, Taiwan \\ ${ }^{5}$ Institute of Toxicology, College of Medicine, National Taiwan University, 1 Jen-Ai Road, Section 1, Taipei 10051, Taiwan
}

Correspondence should be addressed to Jaw-Jou Kang; jjkang@ntu.edu.tw and Yu-Wen Cheng; ywcheng@tmu.edu.tw

Received 30 April 2013; Revised 23 July 2013; Accepted 24 July 2013

Academic Editor: Pradeep Visen

Copyright (c) 2013 Ching-Hao Li et al. This is an open access article distributed under the Creative Commons Attribution License, which permits unrestricted use, distribution, and reproduction in any medium, provided the original work is properly cited.

\begin{abstract}
Tongkat Ali (Eurycoma longifolia) is an indigenous traditional herb in Southern Asia. Its powdered root has been processed to produce health supplements, but no detailed toxicology report is available. In this study, neither mutagenicity nor clastogenicity was noted, and acute oral $\mathrm{LD}_{50}$ was more than $6 \mathrm{~g} / \mathrm{kg}$ b.w. After 4 -week subacute and 13 -week subchronic exposure paradigms (0, 0.6, 1.2 , and $2 \mathrm{~g} / \mathrm{kg}$ b.w./day), adverse effects attributable to test compound were not observed with respect to body weight, hematology, serum biochemistry, urinalysis, macropathology, or histopathology. However, the treatment significantly reduced prothrombin time, partial thromboplastin time, blood urea nitrogen, creatinine, aspartate aminotransferase, creatine phosphate kinase, lactate dehydrogenase, and cholesterol levels, especially in males $(P<0.05)$. These changes were judged as pharmacological effects, and they are beneficial to health. The calculated acceptable daily intake (ADI) was up to $1.2 \mathrm{~g} / \mathrm{adult} / \mathrm{day}$. This information will be useful for product development and safety management.
\end{abstract}

\section{Introduction}

Herbal medicines, originating in China, Europe, and India, have a rich history. Over the last 30 years, the use of herbal medicines as complementary/alternative therapies has become increasingly popular throughout the world. A study in the Journal of the American Medical Association demonstrated that $40 \%$ of US residents regularly use these therapies. These people are well educated and are not dissatisfied with conventional medicines [1].

Eurycoma longifolia Jack (genus: Eurycoma; family: Simaroubaceae) is one of the most popular tropical herbal plants in Southeast Asia countries. In these countries, E. longifolia is identified locally as "Tongkat Ali" or "Malaysia ginseng" (Malaysia), "Pasak Bumi" or "Bedara Pahit" (Indonesia), "Ian-don" (Thailand), and "Cay ba binh" (Vietnam). It is an evergreen, slow-growing shrub with maximum height of $15-$ $18 \mathrm{~m}$, and it is commonly found in tropical forests. After 23 years of cultivation, this dioecious plant, with male and female flowers produced in large panicles on different trees, becomes mature and bears fruit. For commercial uses, their roots are harvested after 4 years of cultivation $[2,3]$. Their roots, stems, and bark are used as folk medicines in different ways for the alleviation of various illnesses, including aches, intermittent fever, sexual insufficiency, dysentery, glandular swelling, and fatigue. Traditionally, the water decoction of E. longifolia root is consumed. Nowadays, more convenient formulas are available, primarily additives mixed with teas and coffees, and over 200 products are available either in the form of raw crude root powder or as capsules mixed with other herbs in the health food market [3]. Some of these products, such as Libidus and Maxidus (which claim to use $E$. 
longifolia as the principal ingredient), have been issued with warnings or even banned in the USA, Canada, and Singapore, because of the lack of science-based safety information, the presence of undeclared prescription drugs, and the use of fake ingredients.

Tongkat Ali, the local name for E. longifolia (in which "Tongkat" meaning "walking stick" refers to the presence of long twisted roots), is known to be enriched with many valuable phytochemicals. More than 65 bioactive compounds have been isolated and characterized, including $\beta$-carboline and canthine-6-one alkaloids, quassinoids (laurycomalactone, eurycomalactone, longilactone, eurylactone, and eurycomanone), squalene derivatives, tirucallane triterpenes, mucopolysaccharides, biphenylneolignans, and eurypeptides [3-5]. Alkaloids and quassinoids comprise majority of the chemical composition and exhibit antimalarial [4], antioxidant [5], antiosteoporotic [6], antidiabetic [7], anticancer [8], antipyretic, and antianxiety activities, some of which have been demonstrated by pharmacological studies. As a health supplement ingredient, the efficacy of E. longifolia in restoring energy, improving muscle strength, alleviating aging males' symptoms [9], and acting as an aphrodisiac on late-onset hypogonadism management [10], has been highlighted. Water-soluble E. longifolia extract was reported to be able to enhance male fertility (with regards to higher semen volumes, spermatozoa count, and motility) in rodents $[11,12]$ and in human trials [13-15]. Scientific evidence proved these efficacies that resulted from the increase in testosterone levels via hypothalamic-pituitary-gonadal axis stimulation [12]. Eurycomanone, the major quassinoids in E. longifolia, enhances testosterone steroidogenesis at the leydig cells by inhibiting aromatase conversion of testosterone to oestrogen [16]. Besides, eurypeptides have been shown to activate the $17 \alpha$-hydroxylase (CYP17 enzyme), triggering the biosynthesis of dehydroepiandrosterone which can act on androgen receptors to initiate the conversion of androstenedione to testosterone $[10,13,17]$. Therefore, E. longifolia supplementation may be an alternative for testosterone replacement therapy and the bone volume restoration from androgen deficient osteoporosis [18-21], or it may be able to improve certain mood state parameters in elders [22].

Although herbal medicines rely on remedies of natural origin and have fewer side effects than allopathic medicines, the use of herbal remedies is not always safe. Hence, concerns about their safety and toxicity are increasing, especially within the context of chronic or cumulative dosing [23]. Numerous commercial E. longifolia supplements do not provide their information about bioactive constituents, extraction methodology, and purity. In general, alcohol extracts (usually enriched eurycomalactone) are more toxic than water extracts $[24,25]$. Although oral toxicity studies show that the lethal dose $50\left(\mathrm{LD}_{50}\right)$ of E. longifolia water extract is at the dosage of $2 \mathrm{~g} / \mathrm{kg}$ b.w. (acute), and that the no observed adverse effect level (NOAEL) is greater than $1 \mathrm{~g} / \mathrm{kg}$ b.w. (28-day subacute feeding) [26] however, to our knowledge, these toxicological reports are incomplete and insufficient for demonstrating either long-term safety or prediction of acceptable daily intake (ADI). To establish evidence-based data, acute, subacute, and subchronic toxicity studies were conducted after single, 4-week, and 13-week repeated oral dosing in Wistar rats, and genotoxic parameters were also evaluated in vitro and in vivo. This study was performed in compliance with the testing guidelines of the Organization for Economic Cooperation and Development (OECD) and the Taiwan Food and Drug Administration.

\section{Materials and Methods}

2.1. E. longifolia Powdered Root Preparation. The powder of E. longifolia roots used in this study was supplied by Exclusive Mark (M) Sdn Bhd, Malaysia. Roots, at least 3 inches in diameter, were harvested, washed to remove stones and soil, and sliced by hand. The slices were dried in an oven at $110^{\circ} \mathrm{C}$ for $2 \mathrm{~h}$ and then crushed and ground to a fine powder. The powdered root was vibrated through a 150 -grade mesh and submitted for quality control. The dry powder was stored at room temperature and resuspended in sterile water at the time of use.

2.2. Salmonella/Microsome Reversion Assay: Ames Test. The Salmonella typhimurium histidine auxotrophs TA98, TA100, TA1537, TA1535, and TA102 were purchased from Moltox (TM, USA). Mutagenicity was determined by incorporation method in the presence and absence of S9 metabolic activation [27]. One hundred microliters of each test bacterial culture $\left(10^{9}\right.$ cells $\left./ \mathrm{mL}\right), 2 \mathrm{~mL}$ soft agar $(0.6 \%$ agar, $0.5 \% \mathrm{NaCl}$, $5 \mathrm{mM}$ histidine, and $50 \mathrm{mM}$ biotin, $\left.\mathrm{pH} 7.4,40-50^{\circ} \mathrm{C}\right), 0.5 \mathrm{~mL}$ S9 mixture (if necessary), and test compounds were mixed well in a test tube. Immediately after mixing, the sample was poured into a minimal agar plate (1.5\% agar, Vogel-Bonner E medium containing 2\% glucose). Plates were incubated for $48 \mathrm{~h}$ at $37^{\circ} \mathrm{C}$ in the dark. The revertant colonies were counted macroscopically. A compound was considered positive for mutagenicity only when (i) the number of revertants was at least double the spontaneous yield, (ii) a statistical significance $(P \leq 0.05)$ was found, and (iii) a reproducible positive dose response was present.

2.3. Chromosomal Aberration. Chinese hamster ovary epithelial cells (CHO-K1, ATCC: CCL-61) were plated in $6 \mathrm{~cm}$ dishes at $5 \times 10^{5}$ cells/plate for the $24 \mathrm{~h}$ treatment group. After overnight incubation, cells were treated with vehicle, mitomycin C $(1 \mu \mathrm{g} / \mathrm{mL})$, benzo(a)pyrene $(5 \mu \mathrm{g} / \mathrm{mL})$, or test compounds $(1.25,2.5$, or $5 \mathrm{mg} / \mathrm{mL})$ for $3-24 \mathrm{~h}$, with or without S9. Then, $3 \mathrm{~h}$ after the end of the treatment time, $0.1 \mu \mathrm{g} / \mathrm{mL}$ colcemid was administered, and metaphase chromosomes were prepared as previously described [27]. After trypsinization, cells were treated with $0.9 \%$ sodium citrate at $37^{\circ} \mathrm{C}$ for $10 \mathrm{~min}$, fixed in Carnoy's solution (methanol : acetic acid, $3: 1$ ), and spread on glass slides. Specimens were stained with $3 \%$ Giemsa solution in $0.07 \mathrm{M}$ phosphate buffer ( $\mathrm{pH}$ 6.8) for $30 \mathrm{~min}$. For determination of chromosome aberrations (e.g., chromosome-type gap (G), break (B), and dicentric (D); chromatid-type gap (g), break (b), and exchange (e)), a total of 100 well-spread diploid M1 metaphase cells per treatment were classified and scored. Data were expressed as the total mean number of chromosomal aberrations per treatment \pm SEM from 300 cells scored in 3 independent experiments. 
2.4. Animal Husbandry. Adult 4-6-week-old male and female Wistar rats, weighing 170-200 g, were obtained from BioLASCO Ltd. (Taipei, Taiwan). Male 6-week-old ICR mice were obtained from the Animal Center of National Taiwan University (Taipei, Taiwan). Animals were separated by sex, housed 3-4 per cage, quarantined, and acclimated for 1 week in the housing room under a $12 \mathrm{~h}$ light/dark cycle at $23 \pm$ $1{ }^{\circ} \mathrm{C}$ and $39-43 \%$ relative humidity. Water and food (Rodent LabDiet 5001; PMI Nutrition International, LLC, Richmond, IN, USA) were available ad libitum. All procedures involving the use of animals were in compliance with the "Guide for the Care and Use of Laboratory Animals" (National Academy of Sciences Press, 1996) and approved by the Institutional Animal Care and Use Committee at our institution (Approval no. LAC-97-0146).

2.5. Micronucleus Assay. Male ICR mice $(N=5)$ were administered test compounds orally by gavage at doses of 0.6 , 1.2 , and $2.0 \mathrm{~g} / \mathrm{kg}$ body weight. Negative controls received the vehicle, and positive controls were administered an intraperitoneal injection of $200 \mathrm{mg} / \mathrm{kg}$ body weight cyclophosphamide. Peripheral blood $(10-20 \mu \mathrm{L})$ was sampled from the tail vein at 24,48 , and $72 \mathrm{~h}$ after-dosing, smeared on a glass microscope slide, and stained with acridine orange $(40 \mu \mathrm{g} / \mathrm{mL})$. The prepared slides were immediately examined by fluorescence microscopy. The ratio (\%) of polychromatic erythrocytes (PCEs) to total erythrocytes and the frequency of micronucleated polychromatic erythrocytes (MNPCEs; $\%$ ) were calculated by counting a total of 1000 erythrocytes or PCEs per animal, respectively.

2.6. Single-Dose Acute Toxicity Study. Forty healthy Wistar rats were divided into 5 groups ( 4 males and 4 females per group). The first group (control) received sterile water, given orally. Groups 2-5 were orally treated with test compounds in doses of $1,2,4$, and $6 \mathrm{~g} / \mathrm{kg}$, respectively. Animals were observed for general behavioral and body weight changes, hazardous symptoms, and mortality for a 14-day period after treatment. At the end of the study (on day 14), rats were anesthetized with isoflurane, blood (for serum biochemistry analysis) was collected from the abdominal aorta, and gross necropsies were conducted.

2.7. 4-Week Subacute and 13-Week Subchronic Toxicity Studies. Healthy Wistar rats were randomly divided into 4 groups. Group 1 (control) animals received vehicle treatment by oral gavage throughout the course of the study. Animals in groups 2-4 were orally administered test compound at doses of 0.6 , 1.2 , and $2 \mathrm{~g} / \mathrm{kg}$ body weight/day for 4 weeks (10 males per group) or 13 weeks (10 males +10 females per group). Body weight, food consumption, and water intake (by subtracting the weight of the remaining food/water from the weight of the supplied food/water) were recorded weekly. Mortality and signs of abnormalities were observed twice daily. At the end of the study, rats were fasted overnight (with water still supplied ad libitum) and anesthetized with isoflurane. Blood samples were obtained from the abdominal aorta using capillary tubes for hematological, clotting, and serum biochemical studies.
2.8. Hematological, Clotting, and Serum Biochemical Analysis. Hematological profiles were obtained using an automatic analyzer (Sysmex K-4500, TOA Medical Electronics Co., Kobe, Japan). Before serum biochemistry (Express Plus automatic clinical chemistry analyzer, Siemens Medical Diagnostics) and clotting (AMAX 200, Trinity Biotec Plc., Ireland) analysis, serum and plasma samples were obtained by centrifugation at $1500 \times \mathrm{g}$ for $10 \mathrm{~min}$. Hematological and serum biochemical analyses were conducted according to the OECD Guidelines for the Testing of Chemicals no. 407 and no. 408.

2.9. Urinalysis. Urinalyses were conducted during the last 4 days of the testing period. Changes in $\mathrm{pH}$, protein and glucose content, specific gravity, uric acid composition, and the presence of occult blood or ketones were assessed (Miditron Junior, Roche, Diagnostics Gmbh, Mannheim, German). Samples were also examined microscopically for the presence of urinary sediments.

2.10. Gross Necropsy. Gross necropsies were performed to analyze macroscopic external and internal features (OECD Guidelines for the Testing of Chemicals no. 407 and no. 408). Vital organs were carefully removed, defatted, and individually weighed and then fixed in $10 \%$ neutral buffered formalin. Organ wet weights were expressed in absolute and relative terms ( $\mathrm{g}$ and $\mathrm{g} / 100 \mathrm{~g}$ body weight or brain weight, resp.).

2.11. Histopathology. The biopsy sections were prepared as described in Supplementary Materials available online at http://dx.doi.org/10.1155/2013/102987 histopathological report and examined by an experienced pathologist. Microscopic features of the organs of male and female rats were compared in the control and $2 \mathrm{~g} / \mathrm{kg}$ body weight-treated groups.

2.12. Statistical Analysis. All values are expressed as the mean \pm SD. Comparisons between groups were performed using one-way analysis of variance (ANOVA) followed by Dunnett multiple comparison tests using SPSS statistical software (DrMarketing Co. Ltd., New Taipei City, Taiwan). A $P$ value of $<0.05$ was considered significant.

\section{Results}

3.1. Neither Mutagenicity nor Clastogenicity Was Caused by E. longifolia Powdered Root Treatment In Vitro and In Vivo. In the Ames test, on increase in the number of revertants was observed in the positive control group $(P<0.05)$. After treatment with various concentrations of E. longifolia powdered root, none of the testing concentrations $(5,2.5,1.25$, 0.625 , or $0.3125 \mathrm{mg} / \mathrm{plate}$ ) resulted in a clear growth in the number of colonies with or without S9 metabolic activation in all 5 test strains (TA97, TA98, TA100, TA102, and TA1535; Table 1).

According to the cell viability assay, the selected testing concentrations $(1.25,2.5$, and $5 \mathrm{mg} / \mathrm{mL})$ were less than the $\mathrm{LC}_{50}$ (Supplementary Table 1). Compared to positive control treatments with mitomycin C $(1 \mu \mathrm{g} / \mathrm{mL}$, without S9 
TABLE 1: Mutagenicity assay of E. longifolia powdered root in vitro (Ames test).

\begin{tabular}{|c|c|c|c|c|c|}
\hline & TA98 & TA100 & TA102 & TA1535 & TA1537 \\
\hline & \multicolumn{5}{|c|}{ Without S9 metabolic activation } \\
\hline Negative $^{1}$ & $22.0 \pm 3.0$ & $141.7 \pm 34.2$ & $202.7 \pm 15.7$ & $11.3 \pm 0.6$ & $6.0 \pm 1.0$ \\
\hline Positive $^{2}$ & $1026.7 \pm 254.0^{*}$ & $3976.0 \pm 644.1^{*}$ & $1274.7 \pm 185.4^{*}$ & $1234.3 \pm 53.8^{*}$ & $762.3 \pm 655.3^{*}$ \\
\hline \multicolumn{6}{|c|}{ E. longifolia powdered root (mg/plate) } \\
\hline 0.3125 & $18.0 \pm 0.0$ & $204.3 \pm 26.0$ & $109.0 \pm 6.9$ & $14.3 \pm 1.2$ & $8.0 \pm 1.7$ \\
\hline 0.625 & $21.7 \pm 5.8$ & $187.3 \pm 48.8$ & $98.0 \pm 10.5$ & $15.7 \pm 3.1$ & $5.7 \pm 0.6$ \\
\hline 1.25 & $20.0 \pm 0.0$ & $187.0 \pm 24.3$ & $103.7 \pm 24.7$ & $18.3 \pm 5.8$ & $6.3 \pm 2.1$ \\
\hline 2.5 & $13.3 \pm 3.2$ & $195.3 \pm 37.5$ & $110.3 \pm 12.4$ & $16.3 \pm 7.6$ & $8.3 \pm 3.1$ \\
\hline \multirow[t]{2}{*}{5} & $18.7 \pm 2.5$ & $184.0 \pm 14.8$ & $98.0 \pm 12.8$ & $22.0 \pm 1.0$ & $8.7 \pm 0.6$ \\
\hline & \multicolumn{5}{|c|}{ With S9 metabolic activation } \\
\hline Negative $^{1}$ & $29.0 \pm 3.6$ & $83.0 \pm 4.4$ & $160.7 \pm 18.3$ & $14.3 \pm 0.6$ & $9.0 \pm 1.0$ \\
\hline Positive $^{2}$ & $100.3 \pm 12.0^{*}$ & $599.7 \pm 49.4^{*}$ & $1565.7 \pm 59.8^{*}$ & $960.3 \pm 71.8^{*}$ & $857.7 \pm 20.4^{*}$ \\
\hline \multicolumn{6}{|c|}{ E. longifolia powdered root (mg/plate) } \\
\hline 0.3125 & $23.0 \pm 5.3$ & $159.7 \pm 14.0$ & $181.7 \pm 8.5$ & $12.3 \pm 6.4$ & $11.7 \pm 3.5$ \\
\hline 0.625 & $23.0 \pm 2.7$ & $171.7 \pm 18.2$ & $129.7 \pm 31.3$ & $10.3 \pm 4.7$ & $7.5 \pm 2.1$ \\
\hline 1.25 & $21.7 \pm 2.1$ & $201.3 \pm 9.3$ & $157.7 \pm 12.5$ & $13.0 \pm 2.7$ & $10.7 \pm 1.2$ \\
\hline 2.5 & $20.3 \pm 3.2$ & $161.3 \pm 35.4$ & $167.3 \pm 15.1$ & $9.3 \pm 6.7$ & $6.3 \pm 3.8$ \\
\hline 5 & $20.7 \pm 3.1$ & $128.3 \pm 29.5$ & $163.3 \pm 7.7$ & $15.7 \pm 6.4$ & $7.3 \pm 2.5$ \\
\hline
\end{tabular}

The values were presented as Mean \pm S.D. $(N \geq 3)$. No significant changes of revertants were observed at any concentrations of test compound treatments in five tester strains. Statistical analysis: ${ }^{*} P<0.05$ indicates a statistical difference with the control group by one-way ANOVA when the number of revertants was twice than control at TA98, TA100, and TA102 and triple than control at TA1537 and TA1535.

${ }^{1}$ Solvent (sterile water) was used as negative control.

${ }^{2}$ Positive control in w/o S9 plate: TA98 (4-nitro-o-phenylenediamine $2.5 \mu \mathrm{g} /$ plate); TA100 and TA1535 (sodium azide $5 \mu \mathrm{g} /$ plate); TA102 (mitomycin C $0.5 \mu \mathrm{g} / \mathrm{plate}$ ); TA1537 (9-aminoacridine $50 \mu \mathrm{g} / \mathrm{plate}) ;$ in w/w S9 plate: TA100/TA102/TA1535/TA1537 (2-aminoanthrene $5 \mu \mathrm{g} / \mathrm{plate}$ ); TA98 (benzo(a)pyrene $5 \mu \mathrm{g} /$ plate).

activation) or benzo(a)pyrene ( $5 \mu \mathrm{g} / \mathrm{mL}$; with $\mathrm{S} 9$ activation), which showed abnormal increases in the number of damaged chromosomes $(P<0.05)$, no increases or irregularities in chromosome aberrations were recorded in all test treatment groups (Table 2).

A reduction in the ratio of PCEs to total erythrocytes (\%) and an increase in the frequency of MNPCEs (\%o) were found in the positive control group $(P<0.05)$. The proportion of PCEs and the frequency of MNPCEs in treated $(0.6,1.2$, and $2 \mathrm{~g} / \mathrm{kg}$ b.w.) groups were not statistically different from those of the negative control animals (Table 3). These data indicated that neither mutagenicity nor clastogenicity was caused by $E$. longifolia powdered root treatments.

3.2. No Deaths or Abnormalities Were Observed in the SingleDose Acute Toxicity Study. No deaths or hazardous signs were recorded in rats during the 14-day observation period for rats orally treated with $E$. longifolia powdered root $(1,2,4$, and $6 \mathrm{~g} / \mathrm{kg}$ b.w.). Hematological and serum biochemical profiles of both sexes, as shown in Supplementary Table 2, remained unaffected.

3.3. E. longifolia Powdered Root Treatment Was Nontoxic but Induced Pharmacological Effects in Subacute and Subchronic Toxicity Studies. No treatment-related mortality or clinical signs of toxicity were observed throughout the 4 - or 13week consecutive testing period (at $0,0.6,1.2$, and $2 \mathrm{~g} / \mathrm{kg}$ b.w.). No statistically significant changes were found in body weight (Supplementary Table 3), food consumption, or water intake (data not shown), regardless of sex or treatment. Most hematology measures (WBC, RBC, Hb, HCT, PLT, MPV, $\mathrm{RDW}$, and $\mathrm{Fbg}$ ) in treated rats were not significantly different from controls, with the exception of marginal variations in certain parameters (MCHC and MCV; Table 4). The PT and APTT of treated males (in both the 4-week and 13-week treatment groups) were significantly decreased compared to control male rats $(P<0.05)$, whereas the PT and APTT were not different in control versus treated female rats (Table 4 and Supplementary Table 4). Serum biochemistry profiles are shown in Table 5. E. longifolia powdered root had no effects on serum electrolytes, such as calcium, potassium, sodium, and chloride, but did cause marginal variations in phosphate and magnesium. No statistically significant differences in liver function parameters (ALT, ALP, and GGT) were noted. However, the activities of AST, CPK, and LDH were reduced in a dose-dependent manner in both 4-week and 13-week treated males $(P<0.05)$. Dose-dependent reductions in kidney function parameters, creatinine, and BUN were noted in male rats treated for 13 weeks (the reduction in BUN was also noted in male rats in the 4-week treatment group) $(P<0.05)$. No similar changes in AST, CPK, LDH, BUN, or creatinine were found in the female groups. Serum cholesterol was significantly decreased in both male and female rats after 4 and 13 weeks of administration $(P<0.05)$. No significant changes in total protein, globulin, albumin, glucose, triglycerides, or amylase were noted. 
TABLE 2: Chromosome aberration assay of E. longifolia powdered root in vitro.

\begin{tabular}{|c|c|c|c|c|c|c|c|}
\hline & \multirow{2}{*}{ Aberrant cells (\%) } & \multicolumn{6}{|c|}{ Number of aberrations/100 cells ${ }^{3-4}$} \\
\hline & & G & $\mathrm{B}$ & $\mathrm{D}$ & g & $\mathrm{b}$ & $\mathrm{e}$ \\
\hline & \multicolumn{7}{|c|}{$3 \mathrm{~h}$ treatment/without $\mathrm{S} 9$ metabolic activation } \\
\hline Negative $^{1}$ & $1.7 \pm 0.6$ & $0.3 \pm 0.3$ & $0.3 \pm 0.3$ & 0 & $0.7 \pm 0.7$ & $0.3 \pm 0.3$ & 0 \\
\hline Positive $^{2}$ & $7.0 \pm 2.7^{*}$ & $0.3 \pm 0.3$ & $0.3 \pm 0.3$ & $0.3 \pm 0.3$ & $1.7 \pm 0.7$ & $0.7 \pm 0.3$ & $3.7 \pm 1.7$ \\
\hline \multicolumn{8}{|c|}{ E. longifolia powdered root $(\mathrm{mg} / \mathrm{mL})$} \\
\hline 1.25 & $1.0 \pm 1.0$ & 0 & 0 & 0 & $0.7 \pm 0.3$ & $0.3 \pm 0.3$ & 0 \\
\hline 2.5 & $0.7 \pm 0.6$ & 0 & 0 & 0 & $0.3 \pm 0.3$ & $0.3 \pm 0.3$ & 0 \\
\hline \multirow[t]{2}{*}{5} & $1.3 \pm 0.6$ & 0 & 0 & 0 & $1.0 \pm 0.6$ & $0.3 \pm 0.3$ & 0 \\
\hline & \multicolumn{7}{|c|}{$3 \mathrm{~h}$ treatment/with S9 metabolic activation } \\
\hline Negative $^{1}$ & $0.7 \pm 1.2$ & 0 & $0.3 \pm 0.3$ & $0.3 \pm 0.3$ & 0 & 0 & 0 \\
\hline Positive $^{2}$ & $5.7 \pm 1.5^{*}$ & 0 & $2.0 \pm 0.6$ & $0.7 \pm 0.7$ & $1.7 \pm 0.3$ & $0.7 \pm 0.7$ & $0.7 \pm 0.3$ \\
\hline \multicolumn{8}{|c|}{ E. longifolia powdered root $(\mathrm{mg} / \mathrm{mL})$} \\
\hline 1.25 & $1.3 \pm 1.2$ & 0 & 0 & 0 & $1.0 \pm 0.6$ & $0.3 \pm 0.3$ & 0 \\
\hline 2.5 & $0.7 \pm 0.6$ & 0 & 0 & 0 & $0.3 \pm 0.3$ & 0 & $0.3 \pm 0.3$ \\
\hline \multirow[t]{2}{*}{5} & $0.7 \pm 0.6$ & $0.3 \pm 0.3$ & 0 & 0 & 0 & $0.3 \pm 0.3$ & 0 \\
\hline & \multicolumn{7}{|c|}{$24 \mathrm{~h}$ treatment/without $S 9$ metabolic activation } \\
\hline Negative $^{1}$ & $0.7 \pm 0.6$ & 0 & 0 & 0 & 0 & $0.7 \pm 0.3$ & 0 \\
\hline Positive $^{2}$ & $9.0 \pm 1.0^{*}$ & $1.3 \pm 0.3$ & $0.7 \pm 0.3$ & 0 & $2.7 \pm 0.9$ & $2.3 \pm 0.7$ & $2.3 \pm 0.7$ \\
\hline \multicolumn{8}{|c|}{ E. longifolia powdered root $(\mathrm{mg} / \mathrm{mL})$} \\
\hline 1.25 & $1.7 \pm 0.6$ & 0 & 0 & 0 & $0.3 \pm 0.3$ & $1.3 \pm 0.3$ & 0 \\
\hline 2.5 & $1.3 \pm 0.6$ & 0 & 0 & 0 & $1.0 \pm 0.7$ & $0.3 \pm 0.3$ & 0 \\
\hline 5 & $1.3 \pm 0.6$ & 0 & 0 & 0 & $0.7 \pm 0.3$ & $0.7 \pm 0.3$ & 0 \\
\hline
\end{tabular}

${ }^{1}$ Solvent (sterile water) was used as negative control.

${ }^{2}$ Positive control in w/o S9 condition: mitomycin C $1 \mu \mathrm{g} / \mathrm{mL}$; in w/w S9 condition: benzo(a)pyrene $5 \mu \mathrm{g} / \mathrm{mL}$.

${ }^{3}$ The chromosomal aberrations were counted by 100 independent cells. For each treatment, at least 300 cells were examined as described in Section 2 . The data are expressed as the Mean \pm SEM $(N=3)$. Significant difference between control treated group at ${ }^{*} P<0.05$ versus control by one-way ANOVA.

${ }^{4} \mathrm{G}$ : chromosome gap; B: chromosome break; D: dicentric; g: gap; b: chromatid break; e: exchange.

TABLE 3: Micronucleus assay of E. longifolia powdered root in vivo.

\begin{tabular}{|c|c|c|c|c|c|c|c|}
\hline \multirow[t]{2}{*}{ Treatment } & \multirow[t]{2}{*}{ Dose } & \multicolumn{3}{|c|}{$\begin{array}{l}\text { Frequency of micronucleated polychromatic } \\
\text { erythrocyte }(\% \circ)\end{array}$} & \multicolumn{3}{|c|}{$\begin{array}{l}\text { Ratio of polychromatic erythrocyte (PCE) to } \\
\text { total erythrocytes }(\%)\end{array}$} \\
\hline & & Day 1 & Day 2 & Day 3 & Day 1 & Day 2 & Day 3 \\
\hline Negative $^{1}$ & 0 & $1.67 \pm 0.58$ & $1.33 \pm 0.63$ & $1.60 \pm 0.76$ & $4.00 \pm 1.00$ & $4.20 \pm 0.84$ & $4.40 \pm 0.89$ \\
\hline $\begin{array}{l}\text { Positive } \\
\text { cyclophosphamide } \\
\text { (mg/kg b.w.) }\end{array}$ & 200 & $10.53 \pm 2.60^{* * *}$ & $12.27 \pm 3.68^{* * *}$ & $10.33 \pm 1.62^{* * *}$ & $1.20 \pm 0.45^{* * *}$ & $1.00 \pm 1.00^{* * *}$ & $0.80 \pm 0.45^{* * *}$ \\
\hline \multirow{3}{*}{$\begin{array}{l}\text { E. longifolia powdered } \\
\operatorname{root}(\mathrm{g} / \mathrm{kg} \text { b.w. })\end{array}$} & 0.6 & $1.67 \pm 0.34$ & $1.13 \pm 0.56$ & $1.53 \pm 0.65$ & $5.60 \pm 1.14$ & $5.20 \pm 0.84$ & $5.40 \pm 0.55$ \\
\hline & 1.2 & $1.80 \pm 0.45$ & $1.46 \pm 0.50$ & $1.13 \pm 0.64$ & $5.20 \pm 0.84$ & $5.40 \pm 0.55$ & $5.20 \pm 0.84$ \\
\hline & 2.0 & $1.60 \pm 0.37$ & $1.93 \pm 0.72$ & $1.47 \pm 0.38$ & $5.20 \pm 0.84$ & $5.00 \pm 0.71$ & $5.20 \pm 0.84$ \\
\hline
\end{tabular}

Both the ratios of polychromatic erythrocyte (PCE) to total erythrocytes (\%) and the frequency of micronucleated polychromatic erythrocyte (\%) in treated group were not statistically different from those of the negative control animals, suggesting that the treatment with $E$. longifolia powdered root did not cause erythropoietic cell toxicity and genotoxicity in vivo. Data were expressed as Mean \pm S.D. $(N=5)$. Statistical analysis: ${ }^{*} P<0.05,{ }^{* *} P<0.01$, and ${ }^{* * *} P<$ 0.001 indicate a statistical difference with the control group by one-way ANOVA.

${ }^{1}$ Mice in negative control group received single gavage of vehicle (sterile water).

Semiquantitative urinalysis (including analysis of urine volume, specific gravity, $\mathrm{pH}$, urobilirubin, protein, glucose, urea acid, ketone, nitro salt, and occult blood) and urinary sediments did not reveal any relevant changes following 4or 13-week administration of E. longifolia powdered root (Supplementary Table 6; data are not shown).
3.4. Treatment with E. longifolia Powdered Root Caused no Macropathological or Histopathological Lesions in Subacute and Subchronic Toxicity Studies. Absolute and relative tissue weights (\% ratio to body weight or brain weight) were not altered by 4- or 13-week treatments (Supplementary Table 5 and Table 6). Macroscopic examination of the vital 


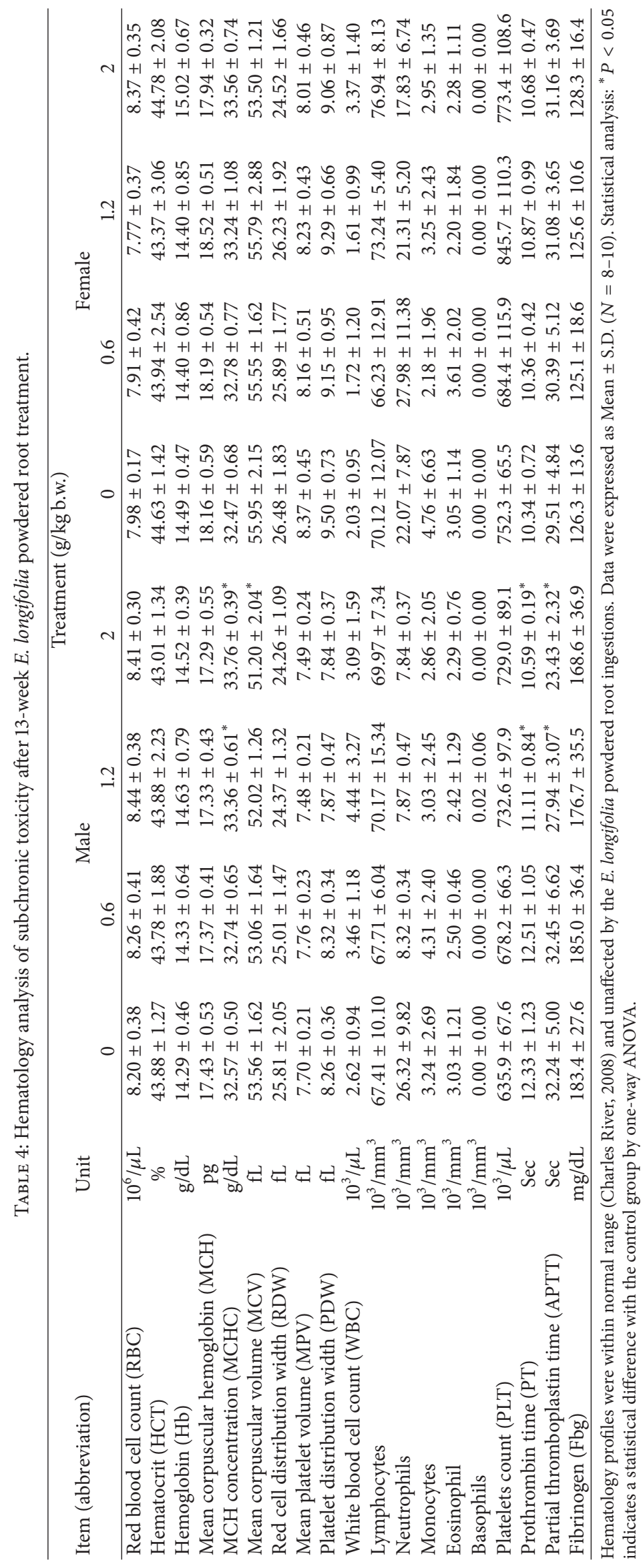




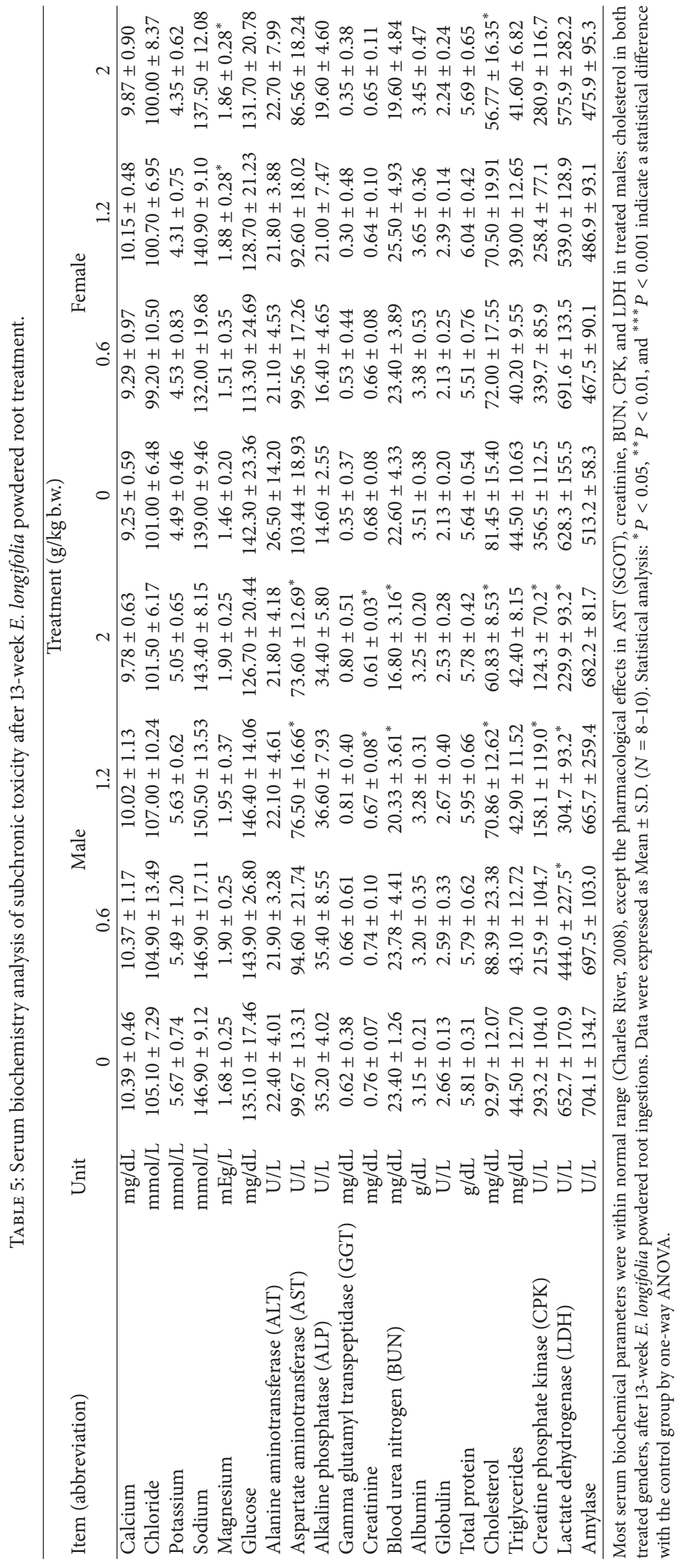




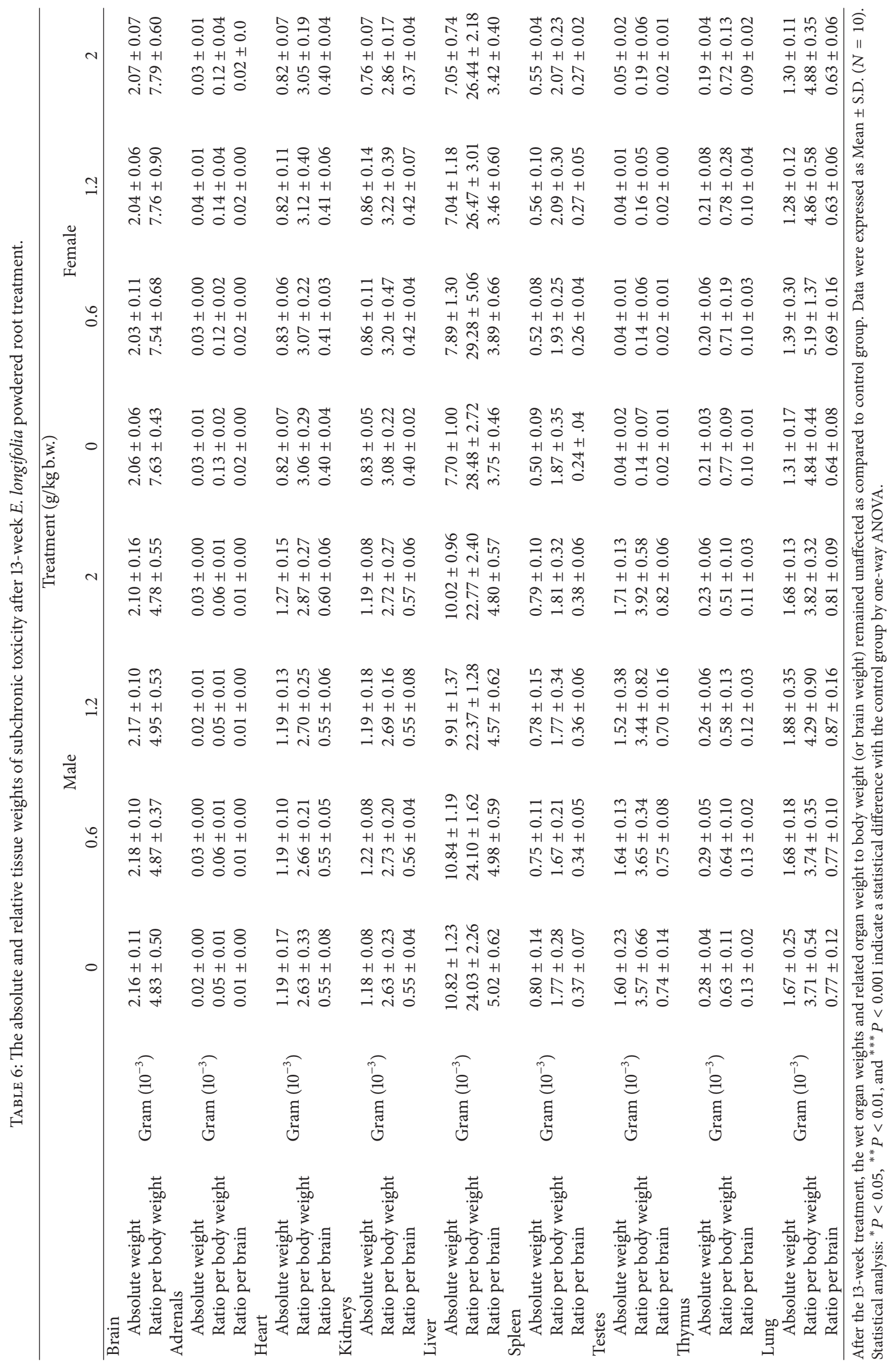


organs of treated animals revealed no abnormalities in color or texture when compared with organs of the control group. Histological evaluation of organs did not reveal any pathological lesions in groups receiving the highest dosage (Supplementary information: histopathological report).

\section{Discussion}

The safety of traditional herbs has been mostly determined by empirical experience. However, the therapeutic dose range of these herbs should be reanalyzed after specific processing procedures (e.g., extraction, dehydration, and capsule or tincture formulations). In the current study, we first determined that the $\mathrm{LD}_{50}$ of E. longifolia powdered root, as measured by oral single-dose administration (the acute toxicity study), was more than $6 \mathrm{~g} / \mathrm{kg}$ b.w. in rats. $E$. longifolia powdered root (6 g/kg b.w.) did not cause any acute toxicities (defined as a rapid onset of symptoms within hours or days) or abnormalities in serum biochemical, hematological, and clotting profiles. However, in previous studies, the reported $\mathrm{LD}_{50}$ of E. longifolia in mice was $1.89 \mathrm{~g} / \mathrm{kg}$ (orally administered, $50 \%$ aqueous ethanolic extract), and on further fractionation, $\mathrm{LD}_{50}$ values were $1.36 \mathrm{~g} / \mathrm{kg}$ (n-butanol fraction), $2.31 \mathrm{~g} / \mathrm{kg}$ (diethyl ether fraction), and $5.27 \mathrm{~g} / \mathrm{kg}$ (water fraction). Eurycomanone, the main component identified in the n-butanol fraction, is the most toxic constituent of E. longifolia $\left(\mathrm{LD}_{50}=0.05 \mathrm{~g} / \mathrm{kg}\right)$ [28]. These discrepancies in the $\mathrm{LD}_{50}$ values reported in different studies resulted from variations in the testing system, especially with respect to animal species and preparation of test compounds. Studies have shown that extracts prepared using organic solvents were more toxic than water extracts $[24,25,28,29]$.

In cumulative, subacute (4-week), and subchronic (13week) studies, E. longifolia powdered root was found to be nontoxic to liver/renal function, and hematological profiles, lipid profiles, body electrolytes, and coagulation factors were not altered. However, dose-related (as well as dosing periodrelated) changes in several serum biochemical parameters were observed. Decreases in LDH, CPK, AST, CRE, and BUN levels in treated groups $(P<0.05)$ explain the cytoprotective potential of E. longifolia, especially in the liver and kidneys. This cytoprotective potential may be due to the pharmacological effects of superoxide dismutase, $\beta$-carboline alkaloids, and squalene derivatives. These compounds are known to be effective scavengers of reactive oxygen species and have significant protective effects against oxidative damage, lipid peroxidation, and inflammation [5, 30-33]. The powdered root of E. longifolia also caused decreases in PT, APTT (in plasma), and cholesterol levels (in serum) in this study $(P<$ 0.05 ) and improved HDL levels in volunteers in a separate study [34]. $\beta$-Carboline alkaloids can act as antithrombotic agents that inhibit platelet coagulation [35]. Squalene is a well-known precursor of cholesterol biosynthesis and has therapeutic potential in the prevention of hypercholesterolemia and cardiovascular disease [33]. More interestingly, except in the case of serum cholesterol level, these changes were observed only in dosed males. In previous studies on the aphrodisiac properties of E. longifolia, an enhancement in sexual behavior was found only in male rats and mice
$[11,36]$, and an increase in testosterone production was found in men [13]. No similar report in women (or female rodents) has been documented. E. longifolia supplementation failed to preserve the bone microarchitecture in orchidectomized rat model [20]. These data suggest that the pharmacological effects of E. longifolia may be sex specific.

In a double-blind, placebo-controlled clinical trial (using $200-600 \mathrm{mg} / \mathrm{kg}$ water extracted E. longifolia root) in volunteers with type 2 diabetes, this herbal treatment had obvious effects on the lowering of blood glucose [34]. Similar results were also observed in hyperglycemic rats treated with aqueous E. longifolia extracts $(50-150 \mathrm{mg} / \mathrm{kg})$ or freezedried powder $(6.25 \mathrm{mg} / \mathrm{kg})$; no reduction in blood glucose was noted in normoglycemic rats with the same treatment, suggesting that E. longifolia may have significant antidiabetic therapeutic potential [7]. In this study, blood glucose levels were unaffected after 4 or 13 weeks of E. longifolia powdered root treatment.

Aristolochic acid nephropathy is a typical example of chronic toxicity due to cumulative genetic damage. Symptoms of this damage can be delayed for years, even after stopping the use of the toxic herbs [23]. $\beta$-Carboline alkaloids have been reported to be mutagenic and genotoxic $[37,38]$. In a previous study, although the revertants induced by $E$. longifolia $(250 \mu \mathrm{g} / \mathrm{mL}$; methanol/chloroform extracts) were not significantly different from the control, a higher level of mutagenicity was noted, suggesting that some active components of E. longifolia may be mutagenic but are present at very low concentrations [39]. In the current study, mutagenicity (Ames test) and clastogenicity (chromosomal aberrations in vitro and micronucleus test in vivo) were determined in accordance with international guidelines. Neither mutagenic nor clastogenic effects were found in vitro (at concentrations up to $5 \mathrm{mg} /$ plate or $5 \mathrm{mg} / \mathrm{mL}$ ) or in vivo (at doses up to $2 \mathrm{~g} / \mathrm{kg}$ b.w.), suggesting that E. longifolia powdered root is not genotoxic.

In addition, E. longifolia crude extracts displayed cytotoxic activity (with $\mathrm{IC}_{50}$ values ranging from 10 to $15 \mu \mathrm{g} / \mathrm{mL}$ in different cell types). Isolated quassinoids, such as eurycomalactone and eurycomanone, were found to be highly cytotoxic against a panel of cancer cell lines (with $\mathrm{IC}_{50}$ values ranging from 0.93 to $1.1 \mu \mathrm{M} ; \mathrm{IC}_{50}=3.8 \mu \mathrm{g} / \mathrm{mL}$ in HepG2 cells, $\mathrm{IC}_{50}=15.2 \mu \mathrm{g} / \mathrm{mL}$ in MCF-7 cells), but they had a certain degree of cytoselectivity in noncancerous or normal cells $\left(\mathrm{IC}_{50}=17 \mu \mathrm{g} / \mathrm{mL}\right.$ in Chang's liver cells, $\mathrm{IC}_{50}=66.3 \mu \mathrm{g} / \mathrm{mL}$ in MCF-10A cells) [40, 41]. The involvement of p53/Bax signaling and downregulation of cancer markers (such as $\mathrm{Bcl}-2$ heterogeneous nuclear ribonucleoprotein A2/B1, prohibitin, and annexin) has been shown to be involved in eurycomanone-induced apoptosis $[40,42]$ and anchorageindependent growth inhibition [8]. Although E. longifolia extracts have been shown to have strong cytotoxic potential, no cytotoxic biomarkers were noted after 13-week exposure in our current study. In past studies, high in vivo cytotoxicity was identified in rodents injected intraperitoneally with $E$. longifolia $(2.44 \mu \mathrm{mol} / \mathrm{kg} /$ day for 3 consecutive days). Highly toxic quassinoids showed poor oral bioavailability in rat models [43] and bypassed first-pass liver metabolism when given by intraperitoneal. Hence, toxicity decreased by approximately 
100-fold if taken orally [3]. This finding supports that, for efficacy and safety purposes, E. longifolia powdered root should only be consumed orally.

Currently, long-term consumption of E. longifolia root extract has been associated with sleep apnea, facial flushing, pressure in the testicles, and hyperaggressiveness. However, no scientific evidence supporting these side effects has been found. Furthermore, no detailed clinical evidence supports the use of specific doses of E. longifolia. According to the recommended intake for humans, a dosage of 100-600 mg/day (water extract) exerted pharmacological effects in men after 2-8 weeks of supplementation [34], and a reference daily dose level of $270-350 \mathrm{mg} / \mathrm{kg}$ was found to be rather safe [3]. In this study, toxicity assessments were based on standard guidelines that can be easily comparable between laboratories. Our data showed that neither acute nor subchronic/delayed toxicity was found. Therefore, a dose of $2 \mathrm{~g} / \mathrm{kg}$ b.w./day of E. longifolia powdered root, generated from our 13-week subchronic toxicity study, can be considered as a no observed adverse effect level (NOAEL). The calculated acceptable daily intake (ADI) is up to $1.2 \mathrm{~g} / 60 \mathrm{~kg}$ adult/day (with a safety factor of $100)$, equivalent to 12 times the recommended intake dosage for humans (100 mg/60 kg adult/day). This information will be useful in the development of E. longifolia products and management of the safety profile for this herbal medicine.

\section{Conclusion}

Eurycoma longifolia powdered root is not genotoxic. The acute oral $\mathrm{LD}_{50}$ was more than $6 \mathrm{~g} / \mathrm{kg}$ b.w. No test compound related toxicity was found after 13-week consecutive exposure. Anticoagulation and liver/kidney cytoprotection were noted in treated males. The calculated acceptable daily intake was up to $1.2 \mathrm{~g} /$ adult/day.

\section{Abbreviations}

PT: $\quad$ Prothrombin time

APTT: Partial thromboplastin time

BUN: Blood urea nitrogen

AST: Aspartate aminotransferase

SGOT: Serum glutamic-oxaloacetic transaminase

ALT: $\quad$ Alanine aminotransferase

SGPT: $\quad$ Serum glutamic-pyruvic transaminase

ALP: Alkaline phosphatase

GGT: Gamma glutamyl transpeptidase

CPK: $\quad$ Creatine phosphate kinase

LDH: $\quad$ Lactate dehydrogenase

NOAEL: No observed adverse effect level

ADI: Acceptable daily intake

$\mathrm{LD}_{50}$ : Lethal dose 50

PCEs: Polychromatic erythrocytes

MNPCEs: Micronucleated polychromatic erythrocytes.

\section{Acknowledgments}

This study was supported by a grant from Exclusive Mark (M) Sdn Bhd, Malaysia (including the test article preparation).
The study designation, operation, and analysis were performed by qualified staff, and the conclusion was made equitably and rationally (without being influenced by founder).

\section{References}

[1] J. A. Astin, "Why patients use alternative medicine: results of a national study," Journal of the American Medical Association, vol. 279, no. 19, pp. 1548-1553, 1998.

[2] A. Osman, B. Jordan, P. A. Lessard et al., "Genetic diversity of Eurycoma longifolia inferred from single nucleotide polymorphisms," Plant Physiology, vol. 131, no. 3, pp. 1294-1301, 2003.

[3] R. Bhat and A. A. Karim, "Tongkat Ali (Eurycoma longifolia Jack): a review on its ethnobotany and pharmacological importance," Fitoterapia, vol. 81, no. 7, pp. 669-679, 2010.

[4] P.-C. Kuo, A. G. Damu, K.-H. Lee, and T.-S. Wu, "Cytotoxic and antimalarial constituents from the roots of Eurycoma longifolia," Bioorganic and Medicinal Chemistry, vol. 12, no. 3, pp. 537-544, 2004.

[5] N. M. Effendy, N. Mohamed, N. Muhammad, I. N. Mohamad, and A. N. Shuid, "Eurycoma longifolia: medicinal plant in the prevention and treatment of male osteoporosis due to androgen deficiency," Evidence-Based Complementary and Alternative Medicine, vol. 2012, Article ID 125761, 9 pages, 2012.

[6] A. N. Shuid, M. F. Abu Bakar, T. A. Abdul Shukor, N. Muhammad, N. Mohamed, and I. N. Soelaiman, "The anti-osteoporotic effect of Eurycoma longifolia in aged orchidectomised rat model," Aging Male, vol. 14, no. 3, pp. 150-154, 2011.

[7] R. Husen, A. H. L. Pihie, and M. Nallappan, "Screening for antihyperglycaemic activity in several local herbs of Malaysia," Journal of Ethnopharmacology, vol. 95, no. 2-3, pp. 205-208, 2004.

[8] P.-F. Wong, W.-F. Cheong, M.-H. Shu, C.-H. Teh, K.-L. Chan, and S. Abubakar, "Eurycomanone suppresses expression of lung cancer cell tumor markers, prohibitin, annexin 1 and endoplasmic reticulum protein 28," Phytomedicine, vol. 19, no. 2, pp. 138144, 2012.

[9] R. R. Henkel, R. Wang, S. H. Bassett et al., "Tongkat Ali as a potential herbal supplement for physically active male and female seniors-a pilot study," Phytotherapy Research, 2013.

[10] M. I. B. M. Tambi, M. K. Imran, and R. R. Henkel, "Standardised water-soluble extract of Eurycoma longifolia, Tongkat ali, as testosterone booster for managing men with late-onset hypogonadism?" Andrologia, vol. 44, supplement 1, pp. 226-230, 2012.

[11] N. A. Wahab, N. M. Mokhtar, W. N. H. A. Halim, and S. Das, "The effect of Eurycoma longifolia jack on spermatogenesis in estrogen-treated rats," Clinics, vol. 65, no. 1, pp. 93-98, 2010.

[12] B. S. Low, P. K. Das, and K. L. Chan, "Standardized quassinoidrich Eurycoma longifolia extract improved spermatogenesis and fertility in male rats via the hypothalamic-pituitary-gonadal axis," Journal of Ethnopharmacology, vol. 145, no. 3, pp. 706-714, 2013.

[13] M. I. Bin Mohd Tambi and M. K. Imran, "Eurycoma longifolia Jack in managing idiopathic male infertility," Asian Journal of Andrology, vol. 12, no. 3, pp. 376-380, 2010.

[14] N. Erasmus, M. C. Solomon, K. A. Fortuin et al., "Effect of Eurycoma longifolia Jack (Tongkat ali) extract on human spermatozoa in vitro," Andrologia, vol. 44, no. 5, pp. 308-314, 2012.

[15] S. B. Ismail, W. M. Wan Mohammad, A. George et al., "Randomized clinical trial on the use of PHYSTA freeze-dried water extract of Eurycoma longifolia for the improvement of 
quality of life and sexual well-being in men," Evidence-Based Complementary and Alternative Medicine, vol. 2012, Article ID 429268, 10 pages, 2012.

[16] B. S. Low, S. B. Choi, H. A. Wahab, P. K. Dasd, and K.-L. Chan, "Eurycomanone, the major quassinoid in Eurycoma longifolia root extract increases spermatogenesis by inhibiting the activity of phosphodiesterase and aromatase in steroidogenesis," Journal of Ethnopharmacology, 2013.

[17] M. I. Tambi, M. K. Imran, and R. R. Henkel, "Standardised water-soluble extract of Eurycoma longifolia, Tongkat ali, as testosterone booster for men with late-onset hypogonadism," Andrologia, vol. 44, pp. 226-230, 2011.

[18] M. Abdulghani, A. H. Hussin, S. A. Sulaiman et al., "The ameliorative effects of Eurycoma longifolia Jack on testosteroneinduced reproductive disorders in female rats," Reproductive Biology, vol. 12, no. 2, pp. 247-255, 2012.

[19] R. Ramli, M. F. Khamis, and A. N. Shuid, "Bone micro-CT assessments in an orchidectomised rat model supplemented with Eurycoma longifolia," Evidence-Based Complementary and Alternative Medicine, vol. 2012, Article ID 501858, 9 pages, 2012.

[20] A. S. Tajul Ariff, I. N. Soelaiman, J. Pramanik, and A. N. Shuid, "Effects of Eurycoma longifolia on testosterone level and bone structure in an aged orchidectomised rat model," EvidenceBased Complementary and Alternative Medicine, vol. 2012, Article ID 818072, 7 pages, 2012.

[21] H. Saadiah Abdul Razak, A. N. Shuid, and I. Naina Mohamed, "Combined effects of Eurycoma longifolia and testosterone on androgen-deficient osteoporosis in a male rat model," EvidenceBased Complementary and Alternative Medicine, vol. 2012, Article ID 872406, 6 pages, 2012.

[22] S. M. Talbott, J. A. Talbott, A. George et al., "Effect of Tongkat Ali on stress hormones and psychological mood state in moderately stressed subjects," Journal of the International Society of Sports Nutrition, vol. 10, no. 1, article 28, 2013.

[23] D. Shaw, "Toxicological risks of Chinese herbs," Planta Medica, vol. 76, no. 17, pp. 2012-2018, 2010.

[24] J. Satayavivad, S. Noppamas, S. Aimon et al., "Toxicological and antimalaria activity of Eurycoma longifolia Jack extracts in mice," Thai Journal of Phytopharmacy, vol. 5, pp. 14-27, 1998.

[25] A. Athimulam, S. Kumaresan, D. C. Y. Foo, M. R. Sarmidi, and R. A. Aziz, "Modelling and optimization of Eurycoma longifolia water extract production," Food and Bioproducts Processing, vol. 84, no. 2C, pp. 139-149, 2006.

[26] A. N. Shuid, L. K. Siang, T. G. Chin, N. Muhammad, N. Mohamed, and I. N. Soelaiman, "Acute and subacute toxicity studies of Eurycoma longifolia in male rats," International Journal of Pharmacology, vol. 7, no. 5, pp. 641-646, 2011.

[27] Y. W. Cheng, W. W. Lee, C. H. Li, C. C. Lee, and J. J. Kang, "Genotoxicity of motorcycle exhaust particles in vivo and in vitro," Toxicological Sciences, vol. 81, no. 1, pp. 103-111, 2004.

[28] K.-L. Chan and C.-Y. Choo, "The toxicity of some quassinoids from Eurycoma longifolia," Planta Medica, vol. 68, no. 7, pp. 662664, 2002.

[29] M. Y. Nurhanan, L. P. A. Hawariah, A. M. Ilham, and M. A. M. Shukri, "Cytotoxic effects of the root extracts of Eurycoma longifolia Jack," Phytotherapy Research, vol. 19, no. 11, pp. 994996, 2005.

[30] F. Hadjaz, S. Besret, F. Martin-Nizard et al., "Antioxydant activity of $\beta$-carboline derivatives in the LDL oxidation model," European Journal of Medicinal Chemistry, vol. 46, no. 6, pp. 2575-2585, 2011.
[31] A. Augustyniak, G. Bartosz, A. Čipak et al., "Natural and synthetic antioxidants: an updated overview," Free Radical Research, vol. 44, no. 10, pp. 1216-1262, 2010.

[32] D. J. Moura, M. F. Richter, J. M. Boeira, J. A. Pêgas Henriques, and J. Saffi, "Antioxidant properties of $\beta$-carboline alkaloids are related to their antimutagenic and antigenotoxic activities," Mutagenesis, vol. 22, no. 4, pp. 293-302, 2007.

[33] H. N. Bhilwade, N. Tatewaki, H. Nishida, and T. Konishi, "Squalene as novel food factor," Current Pharmaceutical Biotechnology, vol. 11, no. 8, pp. 875-880, 2010.

[34] M. I. Tambi, "Standardized water soluble extract of Eurycoma longifolia (LJ100) on men's health," International Journal of Andrology, vol. 28, supplement 1, pp. 25-44, 2005.

[35] H. Tsuchiya, "Comparative effects of $\alpha$-, $\beta$-, and $\gamma$-carbolines on platelet aggregation and lipid membranes," Journal of Toxicology, vol. 2011, Article ID 151596, 9 pages, 2011.

[36] H. H. Ang, K. L. Lee, and M. Kiyoshi, "Eurycoma longifolia Jack enhances sexual motivation in middle-aged male mice," Journal of Basic and Clinical Physiology and Pharmacology, vol. 14, no. 3, pp. 301-308, 2003.

[37] J. N. Picada, K. V. C. L. Da Silva, B. Erdtmann, A. T. Henriques, and J. A. P. Henriques, "Genotoxic effects of structurally related $\beta$-carboline alkaloids," Mutation Research, vol. 379, no. 2, pp. 135-149, 1997.

[38] J. M. Boeira, A. F. Viana, J. N. Picada, and J. A. P. Henriques, "Genotoxic and recombinogenic activities of the two $\beta$-carboline alkaloids harman and harmine in Saccharomyces cerevisiae," Mutation Research, vol. 500, no. 1-2, pp. 39-48, 2002.

[39] A. R. Mohd-Fuat, E. A. Kofi, and G. G. Allan, "Mutagenic and cytotoxic properties of three herbal plants from Southeast Asia," Tropical Biomedicine, vol. 24, no. 2, pp. 49-59, 2007.

[40] Y. Zakaria, A. Rahmat, A. H. L. Pihie, N. R. Abdullah, and P. J. Houghton, "Eurycomanone induce apoptosis in HepG2 cells via up-regulation of p53," Cancer Cell International, vol. 9, article 16, 2009.

[41] K. Miyake, F. Li, Y. Tezuka, S. Awale, and S. Kadota, "Cytotoxic activity of quassinoids from Eurycoma longifolia," Natural Product Communications, vol. 5, no. 7, pp. 1009-1012, 2010.

[42] T. T. Tee, Y. H. Cheah, and L. P. Hawariah, "F16, a fraction from Eurycoma longifolia Jack extract, induces apoptosis via a caspase-9-independent manner in MCF-7 cells," Anticancer Research, vol. 27, no. 5A, pp. 3425-3430, 2007.

[43] B.-S. Low, B.-H. Ng, W.-P. Choy, K.-H. Yuen, and K.-L. Chan, "Bioavailability and pharmacokinetic studies of eurycomanone from Eurycoma longifolia," Planta Medica, vol. 71, no. 9, pp. 803807, 2005. 


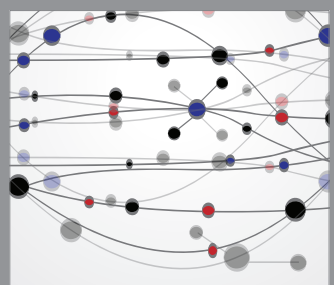

The Scientific World Journal
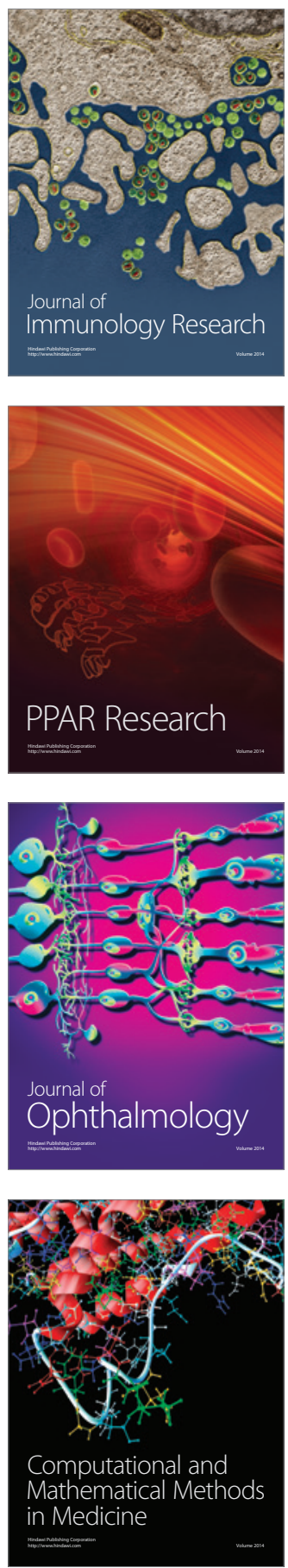

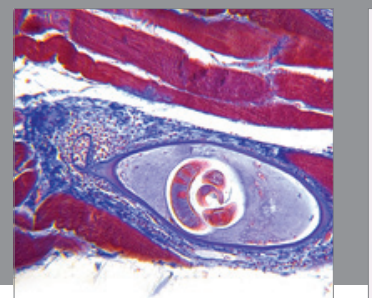

Gastroenterology

Research and Practice
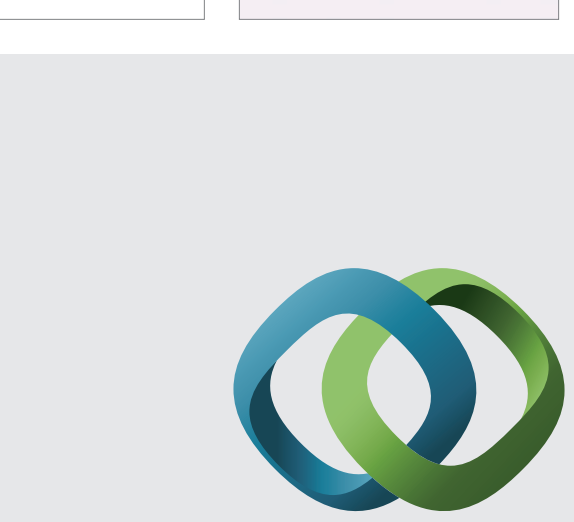

\section{Hindawi}

Submit your manuscripts at

http://www.hindawi.com
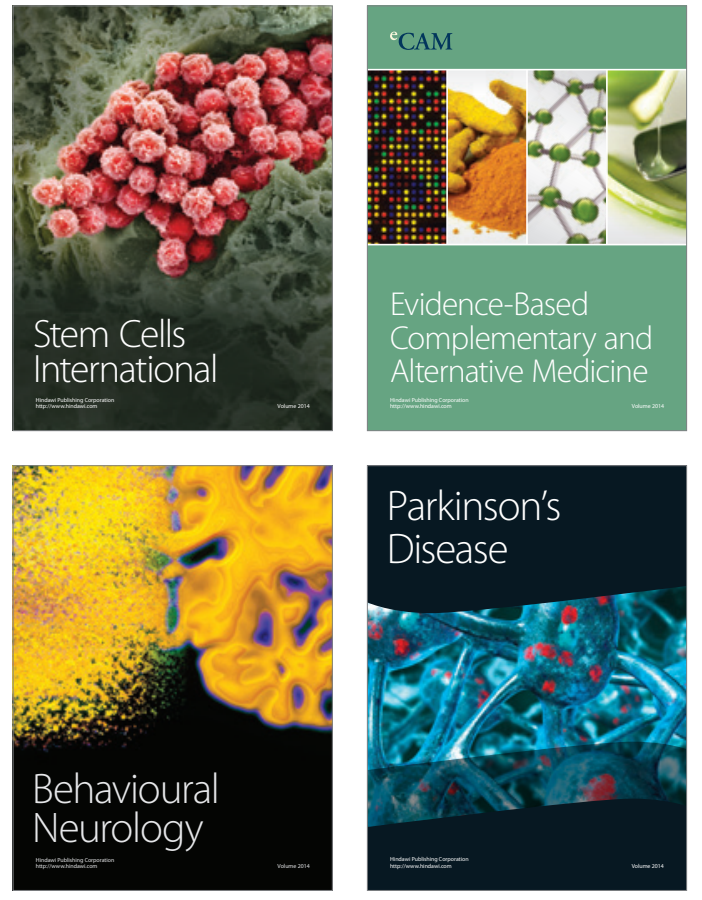
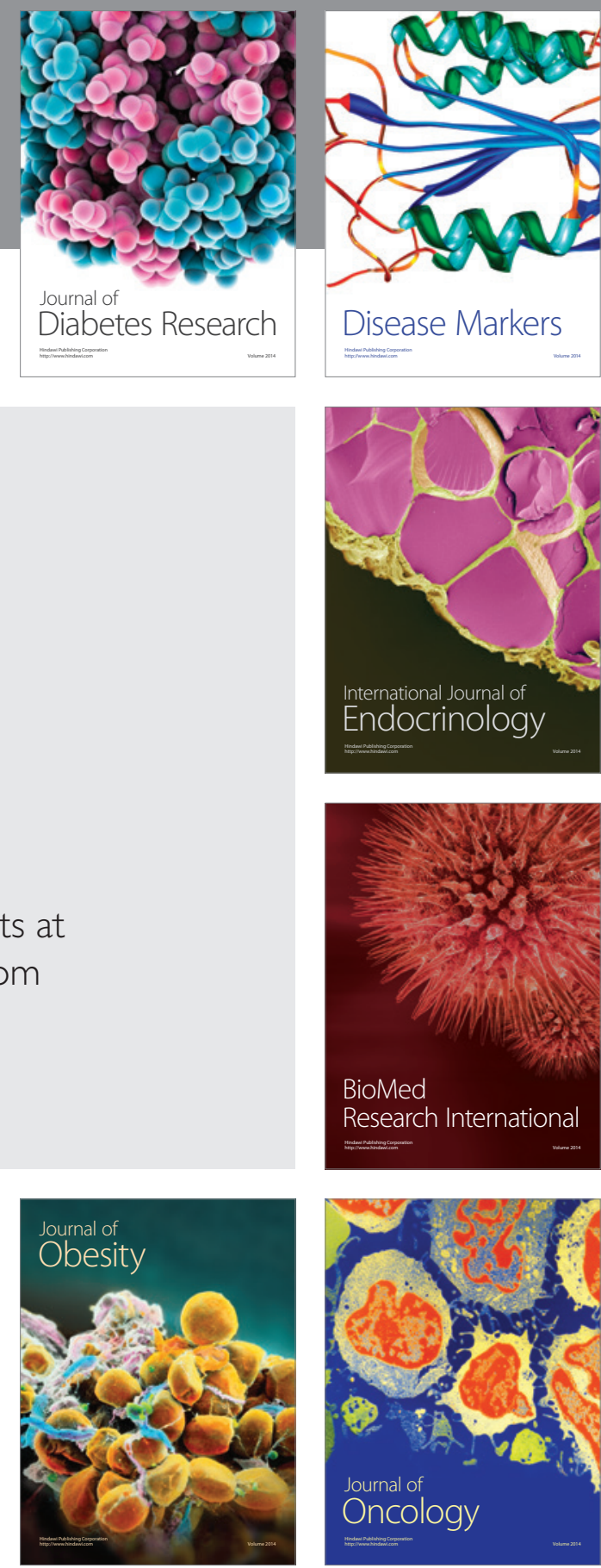

Disease Markers
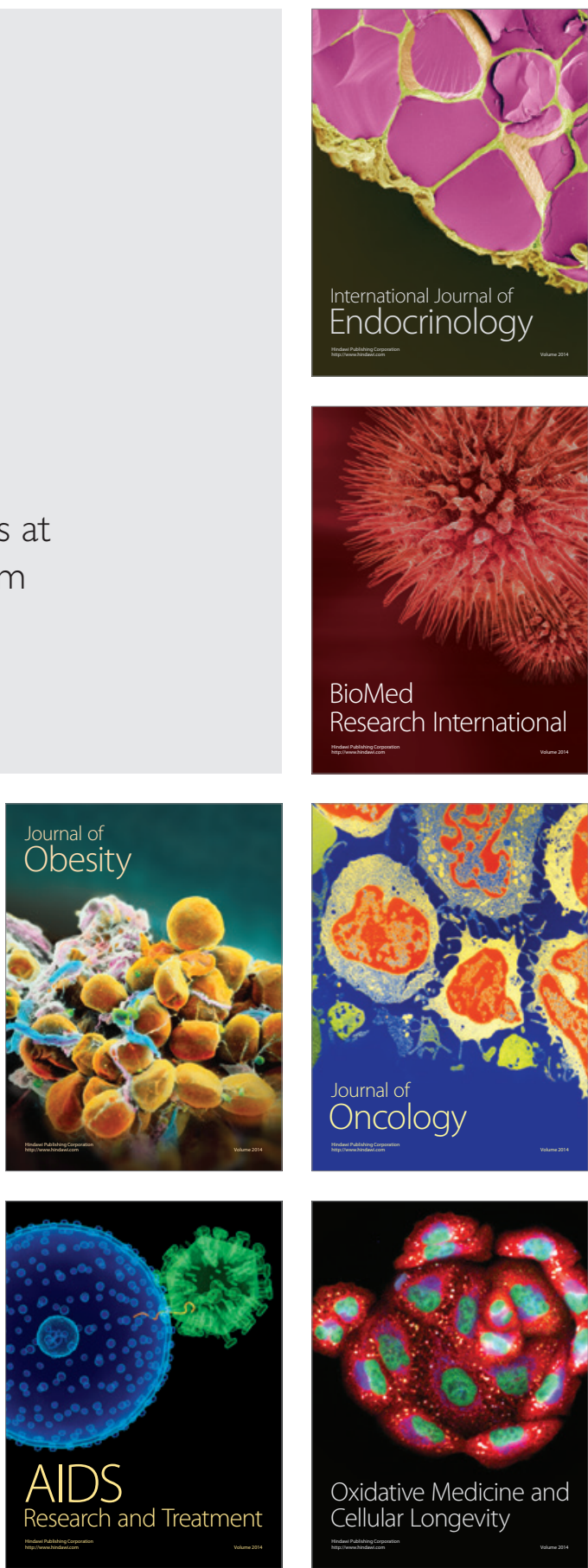